\title{
Ethical Considerations in Agro-biodiversity Research, Collecting, and Use
}

\author{
Johannes M. M. Engels • Hannes Dempewolf • \\ Victoria Henson-Apollonio
}

Accepted: 24 March 2010/Published online: 18 April 2010

(C) The Author(s) 2010. This article is published with open access at Springerlink.com

\begin{abstract}
Humans have always played a crucial role in the evolutionary dynamics of agricultural biodiversity and thus there is a strong relationship between these resources and human cultures. These agricultural resources have long been treated as a global public good, and constitute the livelihoods of millions of predominantly poor people. At the same time, agricultural biodiversity is under serious threat in many parts of the world despite extensive conservation efforts. Ethical considerations regarding the collecting, research, and use of agricultural biodiversity are currently topics of great concern. For example, easy access to genetic resources for breeding purposes is important, but international agreements and legal frameworks are necessary to ensure adequate recognition of the contributions of local communities and traditional farmers in creating and nurturing these resources. Here, we assess ethical principles in the context of existing codes of conduct that are relevant for agro-biodiversity researchers. We aim to create awareness among scientists and policy makers who are concerned with agro-biodiversity research and its potential impact on local communities. We encourage a serious assessment of the ethical principles presented here and hope to facilitate an integration of these principles into the reader's personal ethical framework. Key ethical principles considered here include the importance of obtaining prior informed consent, equity, and the inalienability of rights of local communities and farmers.
\end{abstract}

J. M. M. Engels $(\bowtie) \cdot$ V. Henson-Apollonio

Bioversity International, Via dei Tre Denari, 472/a, Maccarese, 00057 Rome, Italy

e-mail: j.engels@cgiar.org

V. Henson-Apollonio

e-mail: v.henson-apollonio@cgiar.org

H. Dempewolf

Biodiversity Research Centre \& Botany Department, University of British Columbia, 3529-6270 University Blvd, Vancouver, BC V6T 1Z4, Canada

e-mail: handem@interchange.ubc.ca 
Keywords Agricultural biodiversity - Bio-ethics - Genetic resources ·

Traditional knowledge $\cdot$ Access and benefit-sharing International agreements

\section{Introduction}

Until the mid-eighties plant genetic resources for food and agriculture (PGRFA) were regarded as a "heritage of mankind to be preserved and to be freely available for use for the benefit of present and future generations" (Cooper 1993). The principles of "common heritage" and access without restrictions formed the foundation of the International Undertaking on Plant Genetic Resources, a nonbinding agreement that was established by the Member States of the FAO in 1983. Since then, the agreement has been revised several times in order to reflect changes in the viewpoints of member states related to ownership, recognition of the contribution of farmers in developing and maintaining crop germplasm, as well as access and benefit-sharing (ABS), including non-monetary benefits (Raymond and Fowler 2001) of PGRFA. Eventually, this resulted in the binding International Treaty on Plant Genetic Resources for Food and Agriculture (hereinafter referred to as the "International Treaty" or, simply, the "IT") (FAO 2002) that came into effect in 2006. Meanwhile, the implementation of the Convention on Biological Diversity (CBD) in 1993 created a legally binding framework providing general principles for access and benefit-sharing concerning all biological resources. The CBD reaffirms the sovereign rights of nations over their biological resources and establishes the point that nations have the authority to determine access conditions to the genetic resources under their jurisdiction (Bragdon 2004). As a consequence, access without restrictions to genetic/biological resources gradually gave way to much more complex access practices. These access arrangements are handled to an increasing extent through bilateral efforts, which commonly employ legally binding transfer and access agreements. Furthermore, the rapid global increase in the application of intellectual property right (IPR) regimes to protect inventions, novel research (particularly in molecular genetics, genomics, and genetic engineering), and newly produced plant varieties contributes an increasingly popular view of genetic resources as purely economic assets and tradable commodities. This change in emphasis is also reflected in national legislation regarding the access to biological resources (Engels 2006). In contrast to these recent trends, the 2004 International Treaty provides for the establishment of a multilateral system (MLS) of facilitated access where the provider and the recipient of materials do so using a standard material transfer agreement (SMTA). This SMTA was developed and approved by the Governing Body ${ }^{1}$ of the IT and cannot be modified in any way through bilateral negotiations. ${ }^{2}$ The SMTA includes benefit-sharing provisions for those plant genetic resources listed in Annex I of the International Treaty-predominantly crops that

\footnotetext{
${ }^{1}$ The Governing Body of the IT is made up of representatives of all the nations that are members of the IT.

${ }^{2}$ When "material under development is transferred", additional terms and conditions can accompany the SMTA, with the germplasm transfer.
} 
are thought to be of importance for global food security (Moore and Tymowski 2005). Furthermore, the United Nations Declaration on the Rights of Indigenous People addresses rights to the conservation and protection of the environment in order to maintain, control, protect, and develop cultural heritage and traditional knowledge (United Nations 2006).

In the light of these developments, this paper examines ethical principles in the context of research, collecting, conservation, and use of agricultural biodiversity as well as associated information, such as traditional knowledge. In order to obtain access to such resources and information, one must first address questions about ownership and thus the rights of peoples that played a significant role in the generation and subsequent maintenance of these resources and related knowledge. Involving local people and their genetic resources in research activities requires that a particular set of ethical principles be considered. Such ethical principles can include self-determination, inalienability, traditional guardianship, prior informed consent and veto, and confidentiality if desired by the local communities and farmers (See, for example, the guidelines of the International Society of Ethnobiology 2006). In the final part of the paper we assesses to what extent ethical principles have been integrated in existing agreements and partnerships that are foreseen to regulate access and benefitsharing of genetic resources and associated knowledge. We focus here on accessand benefit- sharing (ABS) in particular, since it has been and still is probably the most contentious issue in the current debate, in large part because of the complexity of understanding what constitutes "ownership" over genetic materials that is related to traditional breeding, selection, and farming practices of agricultural crops.

We intend to contribute to the creation of awareness on issues that should be of ethical concern among scientists and policy makers who are concerned with agrobiodiversity research and its potential impact on local communities. We encourage a serious assessment of several ethical principles and hope to facilitate a meaningful integration of these principles into the individual reader's personal ethical framework.

This approach is justified, as a detailed understanding of relevant national and international treaties and instruments may not be known to most researchers. Furthermore, such documents frequently assume prior awareness of such principles or use overly complex and bureaucratic language and thus might not provide much in terms of practical guidance. It is not our intention to suggest novel ethical principles or provide a comprehensive critique of existing ones. Instead, we focus on the practical application of such principles in areas where agro-biodiversity researchers are likely to directly encounter and interact with local people. We are aware that strict adherence to some of the ethical principles cited here could have far reaching consequences for current research and legal practices, such as sharing of benefits with indigenous people, patenting of life forms, and exceedingly high transaction costs, just to name a few. It should be emphasized, however, that we do not aim to directly judge current practices but rather to offer an ethical framework to allow researchers to conclude such judgments on a personal level and to form the basis of discussions with partners in order to reach mutual agreement. 


\section{Peculiarities and Special Facets of Agricultural Biodiversity}

One of the features that distinguishes genetic resources for food and agriculture from biodiversity at large is the crucial role that farmers, have played and, indeed, are still playing in concert with the evolutionary processes that generated these resources (Cooper et al. 1994). This is particularly true of domesticated species. Farmers have influenced the evolutionary processes of individual species throughout their domestication and subsequent selection activities and have hence actively shaped this diversity (Harlan 1975). Crop "varieties", usually landraces, which have been created by farmers and farming communities depend on the people that have produced them for their continued maintenance and survival (Jarvis et al. 2008). Furthermore, these landraces are locally selected and thus, will be well adapted to the specific local environmental and cultural conditions, including agricultural measures and practices that prevail in that region. This dependency on humans does not apply in the same way for non-cultivated species, since their survival rarely depends on human interference. Exceptions have been documented, such as the conservation of a wild oat species (Avena strigosa) dependent on continued cultivation of the cultivated minor crop component (Scholten et al. 2008); grassland and heath ecosystems in Western Europe (Parr et al. 2009).

The above mentioned processes are cumulative; material that has been selected by one farmer or farming community is passed onto others and further changes and improvements are added (Hawkes 1983). In most cases, genetic resources and traditional knowledge of food crops have been accessible to anyone. They generally traveled freely to many parts of the world with migrating people. This was only possible because genetic resources of most major food crops have historically been regarded as "common property". The concept of "ownership", as is currently considered, particularly in Western societies, was unknown. Unrestricted access to these cultivated (and wild) biological resources has allowed them to become adopted by many different cultures and adapted to many different environmental conditions, leading to further diversification. Mixing of seeds possessing different characteristics is one traditional way that farmers manage risk. More recently, i.e., since the early decennia of the twentieth century, unrestricted access to these resources has also allowed scientific breeding to make great progress in producing varieties that can provide sufficient food for an ever-expanding human population. One important consequence of this "globe-trotting habit" and the continuous evolutionary development of genetic resources, is the fact that it is can be difficult to determine precise geographic area(s) where a given variety has obtained its "distinctive properties", as stipulated in the CBD (http://www.cbd.int/doc/legal/cbd-en.pdf). As a result, the application of the concept of "country of origin" as the basis for negotiating access to a domesticated species and to sharing the benefits that eventually derive from its use is challenging in the framework of the CBD (Fowler 2003; Fowler et al. 2004). A similar dilemma exists for varieties that have been bred through scientific breeding, as for example the wheat variety Veery. Based on data supplied by breeders, it can be shown that this variety ${ }^{3}$ is the product of 3,170

\footnotetext{
${ }_{3}^{3}$ Veery has been shown to be a series of closely related varieties (IPGRI 1996).
} 
different crosses involving 51 parents from 26 countries and consists of improved varieties, landraces, and wild relatives of cultivated wheat (International Plant Genetic Resources Institute 1996).

Another consequence of the aforementioned evolutionary processes of crop diversification is the relatively high levels of genetic diversity within many domesticated species - a diversity that has been generated and maintained over hundreds of years during their cultivation across wide and often diverse geographic areas, e.g., agricultural crops like rice and wheat and horticultural crops like tomato and pepper. Although geographic areas with a high degree of diversity both between and within species can be identified-the so-called Vavilovian centers of crop diversity (Vavilov 1926), it is now generally accepted that this widespread genetic diversity is predominantly due to human activity. This phenomenon led Jack Harlan to define "non-centers of diversity" - areas that often comprise many countries and are often spread across large parts of whole continents (Harlan 1971). As a consequence, few countries possess sufficient genetic diversity of any given crop species to be "self-sufficient" with respect to new alleles that will be needed to produce food in the face of changing crop pests and environmental conditions. And, as a result, there is a high degree of interdependence of countries on genetic diversity (Fowler and Hodgkin 2004; FAO in press). Facilitated access is hence an essential condition for crop development and food security. This consideration, among others, was used to suggest the establishment of a multilateral system for PGRFA (Cooper et al. 1994) that would also be consistent with the CBD.

The close relationship between a biological/genetic resource and human culture has over time resulted in a high degree of interdependence of plant varieties and the people that created and continue to maintain them through their active cultivation (Eyzaguirre 2003; Cromwell et al. 2001). Many of these traditional varieties that have evolved over hundreds of years under specific cultivation practices and environmental conditions are localized in their distribution, in some cases even specific to a particular community. When planning to conserve such genetic resources in an ex situ scenario, one should not only collect the existing diversity adequately, but also the associated knowledge from the community or communities concerned. Consequently, questions of property rights over these resources and the associated traditional knowledge as well as related ethical questions need to be addressed when collecting, conserving, and using them in a research context.

With the intensification of agriculture and the development of research-based plant and animal breeding programs, the need for and interest in diverse genetic resources has gradually increased. At the same time, a multitude of factors (e.g., changes in land use; replacement of landraces by modern high yielding varieties; mechanization in agriculture and the need for uniformity; increased economic and research concentration of fewer and fewer crops; infrastructural developments; etc.) have triggered alarm in some groups that there is now a human-induced irreversible loss of many of these important genetic resources (FAO 1998; FAO 2010, in press). This alarm has resulted in intensified conservation efforts, increased support for research activities, and an augmented use of such resources in breeding activities over the past 20-30 years (Laird and ten Kate 2002). 
Consequently, questions have arisen concerning the equitable sharing of benefits derived from the use of these collected biological resources and associated knowledge (Laird 2002)_questions that deserve a proper answer and practical guidance as to what should happen on the ground.

As previously mentioned, agricultural genetic resources have traditionally been regarded as a global public good, a natural asset of which it was generally understood that no one would lose anything by sharing it. Some notable exceptions exist, however, such as the wars that have been fought over access to spicesperhaps an early harbinger of things to come. This demonstrates that alternative views of the "genetic resources as a public good" paradigm have always existed, though rarely for major staple food crops of global importance. In recent years a number of research initiatives have been implemented with a focus on farmers' rights (Salazar et al. 2007; Andersen 2009) as well as on the protection of traditional knowledge and cultural heritage (Swiderska et al. 2009). These initiatives contribute to an increasing awareness of the issue of ownership over genetic resources and the importance of protecting traditional knowledge and cultural heritage and thus, may provide a better basis for the development of sound policies on these matters. Nevertheless, in many cases indigenous peoples, traditional societies, and local communities may not know to value or realize the potential realistic economic value of these resources, especially in terms of commercial use. This lack of knowledge was, and possibly still is, also true at higher government levels. Policymakers in many governments, including in developing countries, have great difficulty in grappling with these issues. An internationally accepted definition of many terms such as "traditional knowledge" and "farmers rights" does not yet exist. There are notable exceptions where national governments have a heightened awareness such as with Ethiopia and coffee, Kenya and Pyrethrum, and Brazil and rubber. Despite existing international agreements (some would say because of international agreements), access to genetic resources and associated knowledge has become more complex and difficult in recent decades as individuals, firms, communities, national governments, and international fora juggle the complexity of increased demands emanating from interest at all levels. Furthermore, empowerment of developing country, as well as of local communities, such as farmers, in such countries, can be problematic and have not been consistent.

Local communities, especially in developing countries, tend to be generally poor in financial capital but rich in human and social capital. The latter consists of traditional knowledge, skills, and institutions that allow communities to make best use of their assets. They generally also have access to physical capital, in the form of their own labor, as well as natural capital, i.e., land, water, and agricultural biodiversity. However, recent developments such as the spread of HIV/AIDs, and the acquisition of arable land by foreign nations and multi-national companies in many developing countries for the production of bio-fuel or food crops have resulted in decreased labor and access of farmers to arable land (Holt-Giménez and Shattuck 2009). However, the genetic resources held by such communities still represent an asset and such assets require maintenance and care. Such care should not be discounted nor go unrecognized. 


\section{Ethical Principles and Considerations}

The Code of Ethics of the International Society of Ethnobiology (ISE) was adopted by resolution of the Annual General Meeting of the ISE in 1998 (ISE 2006). In doing so, the Society acknowledged the fact that research has been undertaken in the past without the sanction or prior consent of indigenous and traditional peoples involved, and that such research has thoughtlessly resulted in wrongful expropriation of cultural and intellectual heritage rights of the affected peoples, causing harm and a violation of rights. The ISE formulated two objectives in its Code of Ethics to commit its membership to work in genuine partnership and collaboration with indigenous peoples, traditional societies, and local communities to avoid these past injustices and to build towards developing positive, beneficial, and harmonious relationships in the field of ethnobiology. The Society also recognizes that culture and language are intrinsically connected to land and territory and that cultural and linguistic diversity are inextricably linked to biological diversity. Its objectives are as follows: (1) To optimize the outcomes and reduce as much as possible the adverse effects of research and related activities that might disrupt or disempower indigenous peoples, traditional societies, and local communities from their customary and chosen lifestyles; and (2) To provide a set of principles to govern the conduct of ethnobiologists engaged in or proposing research in all its forms, especially collation and use of traditional knowledge or collecting of flora, fauna, or any other element found on community lands or territories.

It is for these considerations that, although ethnobiology research is not equated to research and breeding of agricultural crops, we have decided to use these guiding principles of the ISE Code of Ethics as a baseline for our discussion.

Ethical principles must be a core consideration in the development of access and benefit-sharing regimes that are often exclusively governed by a political and legal rational. This is particularly true for access and benefit-sharing regimes concerning plant genetic resources for food and agriculture, especially if we want to have practical ways in which to "do the right thing". We must not forget that these resources are often an integral part of the cultural identity of the indigenous and local people that have generated and maintained them.

Significant changes have occurred over the past two decades with respect to the involvement and participation of local communities and farmers in (agricultural) biodiversity research and conservation. The focus has been shifting from ex situ and strongly technologically based conservation approaches to more people-oriented and participatory in situ conservation approaches at the end of the 1980s. This has led to an increase in conservation research activities involving local communities and farmers. Consequently, relevant ethical considerations and principles that should be considered while collecting or exploring genetic resources, as well as conducting research involving indigenous people, traditional societies, or local communities in such research activities have been identified and are discussed here. Wherever available, we recognize and provide references to ethical codes of conduct and guidelines as adopted by international organizations that deal with policy and legal aspects of agricultural biodiversity as well as with research, conservation, and use. 
1. The principle of prior informed consent (PIC) is one of the key principles that underpins access to biodiversity and related information and knowledge in the Convention on Biological Diversity (Glowka et al. 1994) and has been reflected in important codes of conduct [e.g., the FAO International Code of Conduct for Germplasm Collecting and Transfer (FAO 1994)], legal agreements [e.g., the Acquisition Agreements used by the Centers of the CGIAR (System-wide Genetic Resources Program 2001)], the Preface to the CGIAR Guidelines on the Acquisition and Use of Traditional Knowledge as adopted by the Genetic Resource Policy Committee (Anonymous 2008, http://www.cgiar.org/pdf/grpc_24th_meeting_ minutes.pdf) and in Bioversity International's Ethical Principles (Bioversity International 2009). It is also one of the principles of the Code of Ethics of the International Society of Ethnobiology (ISE) (International Society of Ethnobiology 2006) and of the United Nations Declaration on the Rights of Indigenous Peoples (United Nations 2006). The ISE Code also includes the principle of the right of local communities and people to veto any program, project, or study that affects them. The principles of self-determination and of confidentiality are closely related to PIC, as are two of the 15 principles of the Code of Ethics that recognize the importance of scientists to acknowledge and respect the fundamentally important rights of selfdetermination and confidentiality when dealing with local people and their communities. The latter recognizes that indigenous peoples, at their sole discretion, have the right to exclude from publication and/or to keep confidential any information concerning their culture, traditions, mythologies and spiritual beliefs. An additional principle is included in the Code of Ethics of the ISE that relates to the traditional guardianship of indigenous people recognizing the interconnectedness of humanity with the ecosystems of our planet. It also refers to the obligation and responsibility of indigenous peoples to preserve and maintain their role as traditional guardians of these ecosystems through the maintenance of their cultures, mythologies, spiritual beliefs, and customary practices. We acknowledge that the above principles are "in theory" very acceptable and "in practice" require an altruistic approach by scientists when dealing with indigenous peoples, traditional societies, and local communities.

In the "Draft CGIAR Guidelines for the Acquisition and Use of Traditional Knowledge", the principle of PIC is central and includes the requirements that PIC discussions should include consultation regarding research plans, the ways in which the research results will be shared with the community in a manner that will allow the community to use these results, how research results will be conveyed to other audiences, dispute resolution options, and that the PIC must be memorialized, in writing. Unfortunately, experience shows that the principle of PIC may not always be adhered to and that germplasm material is frequently collected without any consent, neither at the national level nor at the community level.

2. Closely related to the aforementioned point is another principle of the Code of Ethics of ISE, the principle of prior right. This principle recognizes the prior, proprietary rights, and interests of indigenous peoples, traditional societies and local communities over all air, land, water, and waterways, as well as the natural resources within them that these peoples have traditionally inhabited or used. It also recognizes all knowledge, intellectual property, and traditional resource rights 
associated with such resources and their use. This principle of "Farmer's Rights" is a key consideration in the International Treaty and it was one of the aspects debated in the 1980s by many Non-Governmental Organizations (NGOs) as a basis for compensating developing countries and their farmers for the genetic diversity they have generated and nurtured over thousands of years. The Treaty recognizes the "enormous contributions that local and indigenous communities and farmers of all regions of the world, particularly those in the centers of diversity, have made and will continue to make for the conservation and development of plant genetic resources". Article 9.1 and Article 9.2 establish that the contracting parties agree that the responsibility for realizing Farmers' Rights rests with national governments (Moore and Tymowski 2005). The core elements of these Farmers' Rights at the national level may include the protection of traditional knowledge, the right to participate in benefit-sharing, and the right to participate in making decisions regarding PGRFA at the national level. With the considerable shift in the concept of Farmers' Rights from an international to a national responsibility, a provision of international compensation to predominantly developing countries, who are the main custodians of genetic diversity, is lacking. This is an aspect that in the past has been a severe battle ground in the "North-South" conflict on genetic resources.

In the Ethical Principles of Bioversity International, a CGIAR Center formerly known as the International Plant Genetic Resource Institute (IPGRI), Farmers' Rights and the traditional resource rights of local communities are recognized and are duly reflected in the institutional strategy as well as in the institute's research activities. It is also a principle of key consideration in the discussions on Indigenous and Traditional Knowledge as part of the WTO/WIPO process as well as of Article 8(j) of the CBD and of the UN Declaration on the Rights of Indigenous Peoples (Article 26.3).

It should be noted that the principle of prior right of indigenous people is increasingly being violated in a globalized world, where large arable land acquisition by foreign nations, the "privatization" of biota through IPR, the application of restrictive seed regulations, creation of hybrid seed varieties of self-pollinating crops such as rice, and the technology to potentially employ genetic use restriction technologies (GURTs) to generate sterile seed is readily available. Non-governmental organizations and at times also governments are providing resistance to these developments (www.etcgroup.org/ upload/publication/527/01/terminatorbrochure02.pdf).

3. The principle of equity is another key consideration in the CBD and is an important component of the benefit-sharing arrangements that are expected to be established between the researcher or collector and the local people when obtaining and subsequently using agro-biodiversity or local knowledge. It is also one of the principles in the Code of Ethics of the ISE and in the UN Declaration on the Rights of Indigenous Peoples (Articles 28.1 and 28.2), to recognize that indigenous peoples must be fairly and adequately compensated for their contributions to research activities and outcomes involving their knowledge. The FAO Code of Conduct for Germplasm Collecting and Transfer includes the equitable sharing of benefits deriving from the use of collected germplasm. As mentioned in the section on access and benefit-sharing below, it is not always easy or even possible to define the contributions of indigenous peoples to a local crop variety or a piece of traditional 
knowledge. Hence it can be challenging to establish detailed benefit-sharing arrangements. However, it is of paramount importance that indigenous peoples are given appropriate legal representation and access to other necessary resources to enable them to successfully defend their position in such negotiations. The Draft CGIAR Guidelines emphasize that efforts should be made to ensure that communities have the wherewithal to understand the ethical and legal ramifications of conditions resulting from PIC discussions. Another difficulty with this principle of equity is that it might be adhered to at the national level, but that benefits rarely reach the local community level from where the germplasm and associated information were initially collected. This will require adequate and sound national legislation that recognizes the equal rights of all citizens.

4. An important right of indigenous peoples, traditional societies, and local communities is that of inalienability - the right that their traditional territories and the natural resources within them (including related practices and cultures as well as the associated traditional knowledge) should not be affected by the introduction of new but foreign ideas, inventions, knowledge, and other findings. The idea of inalienability of rights has existed for authors of creative works as the "moral rights" aspect of copyright law, as embodied in the requirement of the "integrity" of a created work (Kwall 2009). The indigenous communities should have the right to decide whether or not to accept such an introduction. A similar principle is included in Article 20 of the UN Declaration on the Rights of Indigenous Peoples. An example illustrating a scenario involving this principle is the introduction of new crop varieties with "improved" characteristics such as short stemmed Teff (Eragrostis tef) in Ethiopia. Such varieties were developed in the absence of recognition that Teff straw is a major source of livestock feed during the dry season (personal observations). Any breeding program that aims to cater to traditional farmers must first assess the needs and requirements of these local farmers and make a decision with the intended users of the new variety on the specific breeding objectives for any given crop. The so-called participatory plant breeding approaches that have recently increased in popularity and are being applied in a number of development projects address this principle squarely and are increasingly seen to result in better adapted and more sustainable varieties. The same principle applies to the introduction of genetically modified varieties, which is in many countries an issue of great controversy and continued concern (Engels et al. 2006).

While conducting research activities with and for indigenous peoples, there are a number of other general principles, in addition to the ones mentioned above, that should be observed. Most of these principles are addressed in the Code of Ethics of the International Society of Ethnobiology and include:

5. The principle of active participation-Indigenous peoples are encouraged to actively participate in all phases of the research project from inception to completion, as well as during the application of research results. Furthermore, all projects must be seen as cycles of continuous and ongoing dialogue with indigenous peoples. Participatory plant breeding and research approaches in general are based on this principle;

6. The principle of full disclosure-Indigenous peoples are entitled to be fully informed about the nature, scope, and ultimate purpose of the proposed research. In 
fact, adherence to this principle logically requires informing indigenous peoples and obtaining their consent prior to the intended activity;

7. The principle of respect-Researchers must respect the integrity, morality, and spirituality of the culture, traditions, and relationships of indigenous peoples, and should avoid the imposition of external conceptions and standards. This principle requires an adequate understanding of the culture and traditions of indigenous people prior to the actual implementation of the research;

8. The principle of active protection-Researchers should take active measures to protect and enhance the relationships of indigenous peoples with their environment and thereby promote the maintenance of cultural and biological diversity. This requires adequate understanding of the relationship between indigenous people and the environment and of the impact that research activities might have on this relationship. This also applies to the impact of policies and legislation that might affect indigenous people indirectly and that could well affect this important relationship;

9. The principle of supporting indigenous research-Researchers must recognize, support, and prioritize the efforts of indigenous peoples to undertake their own research and publications and utilize their own collections and databases. Although this principle might require significant effort to implement, it will demonstrate the seriousness of respecting the values of the indigenous people and thus will positively influence the willingness of collaboration;

10. The principle of precaution-This principle acknowledges the complexity of the interactions between cultural and biological communities and advocates taking proactive, anticipatory action to identify and to prevent biological or cultural harms resulting from research activities or outcomes, even if cause-and-effect relationships have not yet been scientifically proven; and

11. The principle of the appropriate restitution of indigenous peoples, should any adverse consequences occur from research activities and outcomes. This principle recognizes that every effort will be made to avoid any adverse consequences to indigenous peoples.

\section{Ethical Considerations of Agro-biodiversity Research on the Institutional Level}

Research on agro-biodiversity has to address ethical questions that may not be commonly dealt with in standard scientific research. This includes issues such as the obligation to protect the knowledge, innovations, and practices of indigenous and local communities. The human, cultural, and environmental dimension of indigenous peoples' rights is being increasingly acknowledged due to the growing recognition of indigenous peoples' intrinsic link with local biodiversity (Laird and Posey 2002). Codes of ethics and research guidelines are important tools to provide practical guidance to researchers. Examples of ethical principles as they have been adopted by international organizations dealing with policy and legal aspects of agricultural biodiversity as well as research, conservation and use, are summarized below. Our intention is to illustrate the degree of "ethical thinking" that underpins such codes. We aim to provide a more concrete basis and/or arguments for ethical 
behavior for scientists involved in research activities that include agricultural biodiversity. Where applicable, comments on those codes are made.

Ethical Issues in Food and Agriculture

The Food and Agricultural Organization of the United Nations (FAO) proposes the following ethical values as most relevant for the production, transformation, and distribution of food and agricultural products:

- The value of food;

- The value of enhanced well-being;

- The value of human health;

- The value of natural resources; and

- The value of nature.

Pressure through population growth and increasing market penetration of ancient systems for the maintenance of common property resources, including fisheries, forestry, genetic resources, and rangelands is increasing. Industrialization of agriculture, the need for increased supplies, and declining prices of farm products result in less expensive food for the urban poor. It may also cause the displacement of smallholders or reduce their livelihoods to bare subsistence. Furthermore crop plants and domestic animals become more genetically uniform when farming practices are reduced to the industrialization of agriculture. While in the past, myriads of smallholders maintained the biodiversity necessary for the continued viability of crops and domestic animals, today national governments and international treaties are the instruments that are increasingly called upon to manage the earth's biodiversity. The concentration of economic power, globalization, human induced change, and novel technologies are all developments that raise profound ethical questions that international bodies, such as the FAO, will have to address when carrying out their mandated activities. A more equitable, ethically-based food and agriculture system must incorporate concerns for three widely accepted goals of the global society, each of which incorporate numerous normative propositions: improved human well-being, protection of the environment, and improved public health. A number of actions are suggested that can help to make progress in building a more equitable and ethical food and agricultural system (FAO 2001). Although the listed ethical values are rather general, they can potentially serve as a sound basis for individual governments when developing policies that address the production, transformation, and distribution of food and agricultural products.

The International Code of Conduct for Germplasm Collecting and Transfer

The International Code of Conduct for Germplasm Collecting and Transfer was developed by the FAO, negotiated by its member nations, and was adopted by the FAO Conference in November 1993 as a voluntary code. It aims to promote the rational collecting and sustainable use of genetic resources, to prevent genetic erosion, and to protect the interests of both donors and collectors of germplasm. The code is based on the principle of national sovereignty over PGR and sets out 
standards and principles to be observed. It proposes procedures to request and/or to issue licenses for collecting missions, provides guidelines for collectors, and extends responsibilities and obligations to the sponsors of collecting missions, the curators of genebanks, and to the users of genetic material. The code is intended to provide guidance to national governments for the collecting and transfer of plant genetic resources until they implement their own national access and benefit-sharing measures. It includes specific topics such as collectors' permits, responsibilities of collectors and appropriate behavior pre-, during, and post-collecting, responsibilities of sponsors, curators, and users, and reporting and monitoring requirements. The code also calls for the participation of farmers and local institutions in the collecting missions and proposes that users of germplasm share the benefits derived from the use of PGR with the host country and its farmers (FAO 1994). This code addresses issues in particular at the national level, to be followed by collectors and researchers and to be reflected in agreements concluded with governments. Hence, this code might justifiably be perceived as "top-down" from the community perspective. The Public Interest Intellectual Property Advisors (PIIPA 2005) published a comprehensive resource manual for bio-prospecting that provides brief summaries as well as the corresponding URLs on bio-prospecting, legal frameworks (including the CBD, TRIPs agreement; the Bonn Guidelines; UPOV, etc.), ethical codes and institutional policies and guidelines for bio-prospecting, negotiation issues, bio-prospecting/ABS case studies, types of ABS agreements, and important contractual terms to consider. It provides a comprehensive guide for any scientist who intends to initiate a prospecting/collecting mission, especially in areas with indigenous people.

\section{The CGIAR's Ethical Principles Relating to Genetic Resources}

The CGIAR's main ethical principles are presented under four headings: (a) Equity, (b) Trusteeship of Genetic Resources, (c) Respect, Responsibility and Integrity in Science, and (d) Social Benefits. These are intended to encapsulate the essential principles followed by the CGIAR in relation to its work on genetic resources and in the pursuance of its goal: "To contribute through agricultural and natural resources research and partnerships to sustainable food security and the alleviation of poverty". These ethical principles were adopted by the CGIAR in May 1998 (Anonymous 2001). As the CGIAR is squarely operating in the public domain and its research activities are supported to a large extent with public funds, the organization aims to produce international public goods that are readily available to all bona fide users across the world. Genetic resources that are being maintained by the Centers of the CGIAR are also regarded as international public goods and the legal status of these collections is recognized as such by the Governing Body of the International Treaty on Plant Genetic Resources for Food and Agriculture.

The DRAFT Guidelines for the Acquisition and Use of Traditional Knowledge by CGIAR Scientists

The Genetic Resource Policy Committee (GRPC) of the CGIAR has put forward a set of guidelines aimed at providing practical recommendations to researchers 
working in CGIAR-supported Centers. These guidelines are based on other guidelines mentioned in this paper and also on practices employed by CGIAR scientists in the field (Anonymous 2008).

They include guidance as to what should be in a PIC document, considerations with regard to publication of traditional knowledge, the need for bringing the research results back to communities for their use, recommendations on access and benefit sharing, and direction regarding proprietary issues.

\section{Bioversity International's "Ethical Principles"}

Bioversity's "Ethical Principles" are a further elaboration of the broad CGIAR principles that are summarized above. This document serves to establish standards and operational principles for the institute and provides guidance for arriving at ethical decisions that are transparent and consistent with the mission of Bioversity International. With regard to the section "Access and empowerment" the following (summarized) principles have been established (Bioversity International 2009): (1) strengthen the link between people and biodiversity and ensure continued access to biodiversity resources; (2) recognize farmers' rights and the traditional resource rights of local communities; (3) adhere to the principle of prior informed consent; (4) practice the fair exchange and safe movement of germplasm; (5) encourage active participation of partners in research and conservation; (6) empower partners through capacity building; (7) give due recognition to all the actors in partnerships. The above listed principles underpin the day-to-day operations of the organization and are duly reflected in all agreements that are being concluded with partners to implement joint project activities.

\section{Ethical Considerations in Existing Access and Benefit-sharing Arrangements}

Disagreements over access and benefit-sharing arrangements are often at the heart of conflicts concerned with the larger issue of ownership over (agro-) biodiversity resources. From a political but also ethical standpoint this discussion becomes especially relevant if the resource is being "managed" by indigenous communities and researchers, often foreign to the community, call for access. Therefore, we believe that this topic deserves special attention and discuss in this section the two most important existing legal frameworks for establishing access and benefitsharing arrangements for agricultural biodiversity and related knowledge.

Access and benefit-sharing arrangements are likely the most important and difficult challenges that the CBD and the IT aim to address. Such arrangements are also meant to govern legal frameworks under which collecting and commercial exploitation of these resources can be authorized by the custodians and owners of the genetic resource on a national level. However, both agreements fall short on providing guidance and instruments for the establishment of benefit-sharing arrangements within a nation.

During the negotiation process of the CBD the specific aspects of PGRFA regarding access and benefit-sharing were not, or were only partially, taken into account. This resulted in a framework agreement that was clearly biased towards 
wild species, with a focus on bio-prospecting issues associated with medicinal and industrial uses, and based on the principle of national sovereignty of states over the biodiversity within the borders of their territories. At the same time, the CBD recognizes the traditional dependence of indigenous and local communities on biological resources and the need to ensure that these communities get to share the benefits arising from the use of their traditional knowledge.

This strong emphasis on national sovereignty has led to bilateral rather than multilateral thinking. Access arrangements ought to be based on "mutually agreed terms" and "prior informed consent". The result of these requirements is that practical access to genetic resources has become more difficult and bureaucratic in several instances and has led to a decline in the number of samples that have been exchanged among countries. In contrast, countries that are not signatories to the $\mathrm{CBD}$, such as the United States, have noted a marked increase in requests for samples (Bretting 2007). With this development of a more restrictive attitude and an increasing importance of bilateral arrangements regarding access to genetic resources, the aforementioned peculiarities of agricultural biodiversity deserve special consideration. This has ultimately led to the negotiations of the IT, as discussed below.

It is often challenging, if not impossible, to establish access and benefit-sharing conditions in a meaningful manner (Fowler 2003; Laird and Posey 2002). This issue becomes even more complex when patent applications or the seeking of other forms of property rights have been claimed on traditional varieties, genes, or gene constructs that are used in the production of varieties or in products derived from those resources (Gepts 2004). These circumstances require special attention regarding access and benefit-sharing conditions when acquisition and material transfer agreements are being negotiated, both at the national level and at the local level with the communities concerned.

These issues have been the subject of much debate in the private breeding sector. This is due in part to the 1991 International Union for the Protection of New Varieties of Plants (UPOV) convention, which stipulates that a breeder who uses a protected variety in his/her breeding program must obtain the authorization for commercialization from the breeder of the original variety if the new variety is essentially derived from the protected variety (International Union for the protection of new varieties of plants 1991). This debate is also pertinent to the use of genetic resources that are formally in the public domain, such as the germplasm collections of the Centers of the CGIAR. These collections have been placed under the auspices of FAO as part of the International Network of Ex Situ Germplasm Collections and also have been recognized in the International Treaty to be in the international public domain. The important question in these cases is how much the genetic composition of a germplasm sample must be changed in order to be granted IPR protection on the modified material (Fowler et al. 2004). This is an issue for much debate, as intellectual property rights stem from practices and judicial interpretations at the national level.

The peculiarities of agricultural biodiversity mentioned above demonstrate its marked difference from biodiversity in general. It is for this very reason that the member states of the CBD, through Resolution 3 of the Nairobi Final Act of the 
CBD in 1992, requested that the FAO negotiate among governments the revision of the International Undertaking on Plant Genetic Resources. This Undertaking, established in 1983, is the predecessor of the International Treaty on Plant Genetic Resources for Food and Agriculture, and is based on the notion of plant genetic resources being a common heritage of mankind. Furthermore the CBD member states asked the FAO to also negotiate the realization of Farmers' Rights and consider the issue of access on mutually agreed terms to plant genetic resources (PGR), including the status of ex situ PGR collections not addressed by the CBD (Bragdon 2004). Consequently, these issues were important elements in the negotiation process of the 2004 International Treaty on Plant Genetic Resources for Food and Agriculture that was created as a legally binding agreement on the conservation, sustainable use, and equitable benefit-sharing of PGRFA (Moore and Tymowski 2005; Cooper 2002). The IT includes a multilateral system of access and benefit-sharing (for 35 selected crop genepools and 29 forages) that addresses the specific requirements of agricultural biodiversity. It recognizes the genetic resources of these selected genepools as "shared" and acknowledges that the country of origin cannot be the basis of benefit-sharing agreements. Hence benefits must also be shared on a multilateral rather than a bilateral basis.

Both internationally binding agreements for those nations and states that are signatories, the CBD and the IT intend to provide a political framework for further access and equitable benefit-sharing agreements. During the first meeting of the Governing Body of the International Treaty in Madrid in 2006, an agreement was reached on a Standard Material Transfer Agreement for germplasm accessions that have been included in the multilateral system (FAO 2006). It should be noted that this SMTA only applies to plant genetic resources that are included in Annex I of the IT and that are under governmental control and management. This means that all the germplasm that is growing in agricultural fields or in natural habitats may not be automatically included and that such germplasm is only available according to national access legislation. The latter is based on the principles that have been established under the CBD and have been agreed upon in the so-called Bonn Guidelines (http://www.cbd.int/doc/legal/cbd-en.pdf). The Bonn Guidelines outline conditions that are more suitable for wild species than for agricultural genetic resources. As a result there is the urgent need for appropriate (legal) access arrangements for PGRFA that are maintained in situ.

The listing of crops in Annex I of the IT has resulted in an increase of conservation efforts specifically targeting these crops and their genetic resources and thereby risking further marginalization of non-Annex I species. Therefore, specific arrangements are urgently needed for conservation as well as access and benefit-sharing frameworks targeting germplasm material not covered by the International Treaty.

\section{Conclusions}

Recognizing the close relationship between agricultural biodiversity and human culture is not only important as a basis for the formulation of ethical principles and 
codes of conduct for researchers, but is also a significant factor when determining policy principles for access and benefit-sharing arrangements. Agricultural biodiversity resources that are being used for non-agricultural purposes, such as medicinal or industrial applications, are not covered by the IT. However, demand for such resources is rising, largely due to technological developments, which has resulted in augmented bio-prospecting and collecting activities. This has lead to increased commercial use of genetic resources, which in turn, has informed access and benefit-sharing legislation, as demonstrated by Laird and ten Kate (2002). Therefore, the establishment of and adherence to ethical rules and principles is becoming ever more important for all types of agricultural biodiversity.

Too little time has passed to be able to comprehensively assess the full implications of a shift in policy regimes that no longer declare genetic resources a global public good but instead emphasize national sovereignty. The possible implications are far-reaching and likely will continue to affect access regimes as well as increase pressure on governments and communities to provide such access on mutually agreed terms. There is reason to believe that the distinction between non-Annex I and Annex I crops in the framework of the IT might have an adverse impact on crop conservation and improvement of unlisted species. This, in turn, could well lead to challenging situations for ongoing crop improvement projects. These implications need to be considered and studied in great detail so as to inform governing bodies, such as the CBD and IT, of their potential impact. In this context of shifting baselines, ethical standards that once were deemed appropriate need to be constantly reassessed. Although the ethical principles stated in this paper will remain valid even in the face of sweeping change, the context in which they apply will likely differ and hence their validity needs to be continuously reasserted by all actors concerned.

With the Declaration of the Rights of Indigenous Peoples of the United Nations as well as with the ongoing implementation processes of the CBD and the IT, there is a continued need for consultation with indigenous peoples, traditional societies, and local communities on ethical issues, in particular regarding access and benefitsharing agreements. These consultations should be reflected in the emerging national access legislations. The existing ethical codes and guides will provide a useful framework for such consultations.

Progress in crop and animal breeding efforts depends heavily on ready access to genetic diversity and, therefore, such access should remain unhampered to the greatest extent possible. The aforementioned agreements should adequately recognize and reflect the contributions that indigenous peoples, traditional societies, and local communities have made to the creation and nurturing of agro-biodiversity resources as well as their rights over and interests in these resources.

Governments and international decision-making bodies should more seriously consider ethical issues related to agro-biodiversity collecting and use, and should make these issues an integral component of legislative decisions. Although bureaucratic measures should be kept to a minimum in order to facilitate access, governments ought to consider whether an agreement with certain ethical principles should be made a default precondition for the granting of permits and other documents that are used to govern germplasm access and exchange. In addition, it is 
not sufficient to address these issues at the national level only. Appropriate legislation is required that deals with these issues at the local and regional level within sovereign nations. With regard to the application of intellectual property rights protection on agricultural biodiversity, it is important that such protections do not impede access to and the subsequent use of the genetic diversity that contributed to the protected variety or breed.

In summary, addressing ethical considerations when dealing with agricultural biodiversity research, collecting, and use is becoming increasingly important, especially as the legal aspects of access to genetic resources are becoming ever more complex. Existing instruments that govern access and benefit-sharing take ethical principles into consideration at the national level, however little legal and ethical guidance exists on how individual researchers ought to deal with local communities and indigenous people. Though individual scientists are often under considerable pressure to speedily produce results and thus might not exercise appropriate levels of ethical scrutiny, they need to be aware of the potentially far-reaching impact of their actions on local communities and indigenous societies. Scientists often hold a special place of respect in our societies and thus have a heightened personal responsibility to foster ethically sound behavior among themselves and their colleagues in accordance with all ethical principles stated above.

Acknowledgments The authors acknowledge the inputs and suggestions made in writing this paper by Orlando de Ponti, Pablo Eyzaguirre, Coosje Hoogendoorn, Jeremy Cherfas, and Paul Neate as well as Anne Bjorkman for editorial help. We would also like to thank the anonymous reviewers for their helpful comments on an earlier version of this paper.

Open Access This article is distributed under the terms of the Creative Commons Attribution Noncommercial License which permits any noncommercial use, distribution, and reproduction in any medium, provided the original author(s) and source are credited.

\section{References}

Andersen, R. (2009). Implementation of Article 9: Farmers' Rights. Information paper for the Third Session of the Governing Body of the International Treaty on Plant Genetic Resources for Food and Agriculture, Tunis, 1-5 June 2009. Rome, Italy: FAO.

Anonymous. (2001). Ethics, equity and genetic resources in the future harvest centres. Rome, Italy: International Plant Genetic Resources Institute.

Anonymous. (2008). Minutes of the Genetic Resources Policy Committee of the Consultative Group on International Agricultural Research 24th meeting, 2008. Bioversity International, Rome, Italy. http://www.cgiar.org/pdf/grpc_24th_meeting_minutes.pdf. Accessed 24 March 2010.

Bioversity International. (2009). Bioversity's guiding principles. http://www.bioversityinternational.org/ about_us/guiding_principles/overview.html. Accessed May 292009.

Bragdon, S. (2004). International Law of Relevance to Plant Genetic Resources: A practical review for scientists and other professionals working with plant genetic resources. Issues in Genetic Resources No. 10. Rome, Italy: International Plant Genetic Resources Institute.

Bretting, P. K. (2007). The U.S. National Plant Germplasm System in an era of shifting international norms for germplasm exchange. Acta Horticulture (ISHS), 760, 55-60.

Convention on Biological Diversity. (1993). http://www.cbd.int/doc/legal/cbd-en.pdf. Accessed 21 March 2010.

Cooper, D. (1993). The International undertaking on plant genetic resources. RECIEL, 2(2), 158-166. 
Cooper, D. (2002). The International Treaty on Plant Genetic Resources for Food and Agriculture. RECIEL (Review of European Community and International Environmental Law).

Cooper, D., Engels, J., \& Frison, E. (1994). A multilateral system for plant genetic resources: Imperatives, achievements and challenges. Issues in Genetic Resources No. 2. Rome, Italy: International Plant Genetic Resources Institute.

Cromwell, E., Cooper, D., \& Mulvany, P. (2001). Agriculture, biodiversity and livelihoods: Issues and entry points. In I. Koziell \& J. Saunders (Eds.), Living off biodiversity: Exploring livelihoods and biodiversity issues in natural resources management (pp. 75-112). London: International Institute for Environment and Development.

Engels, J. M. M. (2006). Technological and policy developments in relation to conservation and use of genetic resources. Indian Journal of Plant Genetic Resources, 19(3), 312-313.

Engels, J. M. M., Ebert, A. W., Thormann, I., \& de Vicente, M. C. (2006). Centres of crop diversity and/ or origin, genetically modified crops and implications for plant genetic resources conservation. Genetic Resources and Crop Evolution, 53(8), 1675-1688.

Eyzaguirre, P. B. (2003). Cultural factors and crop genetic diversity. In CIP-UPWARD conservation and sustainable use of agricultural biodiversity: A sourcebook. International Potato Center-Users' Perspective with Agricultural Research and Development (pp. 39-45). Los Banos, Laguna, Philippines: CIP-UPWARD International Potato Center.

FAO. (1994). International Code of Conduct for Plant Germplasm Collecting and Transfer. Food and Agricultural Organization of the United Nations. http://www.fao.org/ag/agp/agps/pgr/icc/icce.htm. Accessed 29 May 2009.

FAO. (1998). The state of the world's plant genetic resources for food and agriculture. Rome, Italy: Food and Agricultural Organization of the United Nations.

FAO. (2001). Building a more equitable and ethical food and agriculture system. Ethical Issues in food and agriculture. http://www.fao.org/DOCREP/003/X9601E/x9601e07.htm. Accessed 29 May 2009.

FAO. (2002). The international treaty on plant genetic resources for food and agriculture. Rome, Italy: Food and Agricultural Organization of the United Nations.

FAO. (2006). Standard Material Transfer Agreement. ftp://ftp.fao.org/ag/cgrfa/gb1/SMTAe.pdf. Accessed 29 May 2009.

FAO. (2010, in press). State of the world report II, chapter 1-state of diversity. Rome: FAO.

Fowler, C. (2003). Implementing accesses and benefit-sharing procedures under the Convention on Biological Diversity: The dilemma of crop genetic resources and their origins. In GFAR/IPGRI. Strengthening partnerships in agricultural research for development in the context of globalization. Proceedings of the GFAR-2000 Conference, 21-23 May 2000, Dresden, Germany. (pp. 106-114). Rome, Italy: GFAR and IPGRI.

Fowler, C., \& Hodgkin, T. (2004). Plant genetic resources for food and agriculture: Assessing global availability. Annual Review of Environment and Resources, 29, 10.1-10.37.

Fowler, C., Engels, J., \& Frison, E. (2004). The question of derivatives: Promoting use and ensuring availability of non-proprietary plant genetic resources. In Issues in Plant Genetic Resources No. 12. Rome, Italy: International Plant Genetic Resources Institute.

Gepts, P. (2004). Who owns biodiversity, and how should the owners be compensated? Plant Physiology, 134(4), 1295-1307.

Glowka, L., Burhenne-Guilmin, F., Synge, H., Mc Neely, J. A., \& Guendling, L. (1994). A guide to the convention on biological diversity. IUCN Environmental Policy and Paw Paper No. 30. Bonn: IUCN.

Harlan, J. R. (1971). Agricultural origins: Centers and non-centers. Science, 174(4008), 468-474.

Harlan, J. R. (1975). Crops and man. Madison, WI: American Society of Agronomy, Crops Society of America.

Hawkes, J. G. (1983). The diversity of crop plants. Cambridge, MA: Harvard University Press.

Holt-Giménez, E., \& Shattuck, A. (2009). The agrofuels transition restructuring places and spaces in the global food system. Bulletin of Science, Technology \& Society, 29(3), 180-188.

International Plant Genetic Resources Institute. (1996). Access to plant genetic resources and equitable sharing of benefits: A contribution to the debate on systems for the exchange of germplasm. Issues in Genetic Resources No. 4. Rome, Italy: International Plant Genetic Resources Institute.

International Society of Ethnobiology. (2006). International Society of Ethnobiology Code of Ethics (with 2008 additions). http://ise.arts.ubc.ca/global_coalition/ethics.php. Accessed 31 May 2009.

International Union for the protection of new varieties of plants. (1991). International convention for the protection of new varieties of plants. http://www.upov.int/en/publications/conventions/1991/ act1991.htm. Accessed 29 May 2009. 
Jarvis, D. I., Brown, A. H. D., Cuong, P. H., Collado-Panduro, L., Latournerie-Moreno, L., Gyawali, S., et al. (2008). A global perspective of the richness and evenness of traditional crop-variety diversity maintained by farming communities. Proceedings of the National Academy of Sciences, 105(14), 5326-5331.

Kwall, R. R. (2009). The soul of creativity: Forging a moral rights law for the United States. Stanford University Press, Technology, Law \& Culture Research Paper No. 09-008. (Available at SSRN: http://ssrn.com/abstract=1187102).

Laird, S. A. (2002). Biodiversity and traditional knowledge. Equitable partnerships in practice. Peoples and Plant. Conservation Series. London: Earthscan Publication Ltd.

Laird, S. A., \& Posey, D. A. (2002). Professional society standards for biodiversity research: Codes of ethics and research guidelines. In S. A. Laird (Ed.), Biodiversity and traditional knowledge. Equitable partnerships in practice. Peoples and Plant. Conservation Series (pp 16-38). London: Earthscan Publication Ltd.

Laird, S. A., \& ten Kate, K. (2002). Biodiversity prospecting: The commercial use of genetic resources and best practice in benefit-sharing. In S. A. Laird (Ed.), Biodiversity and traditional knowledge. Equitable partnerships in practice. Peoples and Plant. Conservation Series (pp 241-286). London: Earthscan Publication Ltd.

Moore, G., \& Tymowski, W. (2005). Explanatory guide to the International Treaty on Plant Genetic Resources for Food and Agriculture. Gland, Switzerland and Cambridge, UK: IUCN.

Parr, S., O’Donovan, G., Ward, S., \& Finn, J. A. (2009). Vegetation analysis of upland Burren grasslands of conservation interest. Biology \& Environment, 109B, 11-33.

Public Interest Intellectual Property Advisors. (2005). Resource manual. http://www.piipa.org/. Accessed 29 May 2009.

Raymond, R., \& Fowler, C. (2001). Sharing the non-monetary benefits of agricultural biodiversity. Issues in Genetic Resources No. 5. Rome, Italy: International Plant Genetic Resources Institute.

Salazar, R., Louwaars, N. P., \& Visser, B. (2007). Protecting farmers' new varieties: New approaches to rights on collective innovations in plant genetic resources. World Development, 35(9), 1515-1528.

Scholten, M., Maxted, N., Ford-Lloyd, B. V., \& Green, N. (2008). Hebridean and Shetland oat (Avena strigos Schreb.) and Shetland cabbage (Brassica oleracea L.) landraces: Occurrence and conservation issues. Plant Genetic Resources Newsletter, 154, 1-5.

Swiderska, K., Argumedo, A., Pant, R., Vedavathy, S., Munyi, P., Mutta, D. et al. (2009). Protecting traditional knowledge from the grassroots up. IIED Briefing June 2009. London, UK: IIED. www.iied.org/pubs/display.php?o=17067IIED.

System-wide Genetic Resources Program. (2001). Booklet of CGIAR Centre Policy Instruments, Guidelines and Statements on Genetic Resources, Biotechnology and Intellectual Property Rights. Version I. Rome, Italy: System-wide Genetic Resources Programme (SGRP) with the CGIAR Genetic Resources Policy Committee.

United Nations. (2006). United Nations Declaration on the Rights of Indigenous Peoples. Approved by the UN Human Rights Council on 29 June 2006.

Vavilov, N. I. (1926). Studies on the origin of cultivated plants. Bulletin of Applied Botany, Genetics \& Plant Breeding, 16(2), 1-248. 